tension and no evidence of right heart hypertrophy or insufficiency. A number of patients who had had right-sided heart failure, and had recovered, showed similar findings. The blood volume was significantly raised, and there was of course evidence of right ventricular hypertrophy. This marked fall in pulmonary artery pressure on recovery is probably due to relief of the anoxic vasoconstriction, decrease in the blood volume and viscosity, and the reduction of cardiac output. Thus the old concept that rightsided heart failure in these patients is mainly due to irreversible structural damage to pulmonary vessels can no longer be supported. Prompt and active therapeutic measures are life-saving and cause a dramatic reversal of many of the most adverse factors.

Although many cases of severe emphysema are under medical supervision over long periods, it is most unusual for one of these patients to develop a large heart with right ventricular hypertrophy and, finally, failure while under observation. In fact, practically all patients with cor pulmonale due to emphysema are seen for the first time when they are, or have recently been, in heart failure and already have right ventricular hypertrophy. Further, when these patients are studied after recovery a number show a smaller degree of pulmonary distension and a better ventilatory capacity than severely emphysematous patients without cardiac involvement.

I would like to offer a tentative explanation of these facts. If a patient with emphysema suffers from severe ventilatory disability, then this of itself may protect the right ventricle by greatly limiting activity and any resultant pulmonary hypertension due to increased blood flow and, perhaps, severe anoxia. Thus right ventricular hypertrophy and dilatation, which in some ways is the "beginning of the end," does not develop. However, those patients with less ventilatory impairment are not so limited in their activities and are able, without intolerable ventilatory discomfort (dyspnoea), to carry out regularly enough exercise to cause pronounced pulmonary hypertension. Thus right ventricular hypertrophy may develop and any sudden further stress due to infection or added anoxia may cause failure.

Although ventilatory studies help to measure dyspnoea, the most important symptom and disability so far as the patient is concerned, the circulatory aspects of this disease must also be studied, especially when prognosis is being considered. Clinical examination, electrocardiography, and screening make this assessment relatively easy in most cases, without cardiac catheterization, which should be resorved for those who are studying the disease, as well as the patient. Even in cases with moderately good ventilatory function, if there is right ventricular hypertrophy then there is constant danger of heart failure that may be precipitated by one of the almost inevitable respiratory infections that are a feature of this disease. At present there is no general agreement as to whether patients with emphysema should restrict their activities or not. It would be of great use to know whether elaborate and unremitting therapy to improve alveolar ventilation, in an attempt to avoid anoxaemia and pulmonary hypertension, is really worth while. Further work is needed to clarify such problems so that the clinician is better equipped to advise the patient with emphysema.

\section{Pulmonary Fibrosis}

Up to the present pulmonary circulatory studies have been carried out in very few cases of generalized pulmonary fibrosis. Any attempt to assess the disability and prognosis in occupational lung fibrosis must include a thorough study of the effect of the disease upon the pulmonary circulation and the right heart. Electrocardiographic studies are not enough, and the development of pulmonary hypertension, and its relation to exercise, must be determined. In view of the fact that the ventilatory capacity is often not greatly restricted, the safety of encouraging men with pulmonary fibrosis to increase their activity, and even carry out hard physical tasks, should be more carefully considered.

[Part II, with a list of references, will appear in our next issue.]

\section{SYMPATHETIC NERVES AND ECLAMPSIA}

\section{BY}

\section{G. W. THEOBALD, M.D., F.R.C.S.Ed., F.R.C.O.G. M.R.C.P.}

(From St. Luke's Maternity Hospital, Bradford)

It is the rule, rather than the exception, for a woman who suffers from eclampsia at the end of her first pregnancy to have normal subsequent confinements. The earlier the onset of hypertension and proteinuria during pregnancy the more likely is the patient to suffer the same sequence of events in succeeding pregnancies. The onset of this so-called toxaemic state at or about the 30th week of pregnancy is often associated with an unduly small foetus, which does not appear to grow, and which is prone to die in utero, with or without evidence of ante-partum haemorrhage.

These facts are illustrated by the following two case histories; several others could be cited.

Case I.-The patient was aged 36 in 1949 . First pregnancy, 1941 : eclampsia at 32nd week; stillborn premature infant. Second pregnancy, 1944 : eclampsia at 32nd week; S.B. premature infant. Third pregnancy: last menstrual period (L.M.P.) March 4, 1949 ; expected date of delivery (E.D.D.) November 12. On May 26 the blood urea was $20 \mathrm{mg}$. per $100 \mathrm{ml}$; ; urea concentration, $4.4 \%$; intravenous pyelogram, normal. No abnormal cells discovered in urine. July 5 : booked ; B.P., $130 / 80 \mathrm{~mm}$. $\mathrm{Hg}$; urine, N.A.D. ; weight $11 \mathrm{st} .6 \mathrm{lb}$. (72.6 kg.). September 1 : 26 weeks pregnant ; urine, N.A.D. ; B.P., 140/90. From September 1 to October 10 the B.P. varied between $140 / 90$ and $170 / 120$; no proteinuria. October 11: B.P., 180/130; proteinuria ; oedema ; weight, 13 st. 3 lb. (83.9 kg.). October 19: 32 weeks pregnant; alb., ${ }^{*} 11$ parts; oedema; emesis. Caesarean section: male infant, $4 \mathrm{lb} .3 \mathrm{oz}$. (1.9 kg.), died from pulmonary atelectasis. November 25: B.P., 140/70; urine, N.A.D. ; very well.

This patient, influenced largely by her doctor and her husband, refused to have her iliac vessels denervated and asked instead to be sterilized.

Case II.-This patient, aged 25, had Raynaud's disease, Bilateral cervical sympathectomy had been successfully carried out in 1950.

First pregnancy, 1949 (in Sunderland): 30th week. B.P., $166 / 110$; alb., 2-8 parts; oedema of ankles. April 3: spontaneous delivery; stillborn (S.B.) foetus, $3 \mathrm{lb} .2 \mathrm{oz}$. (1.4 kg.). Second pregnancy, March, 1950: an abortion. Third pregnancy, 1951 : L.M.P., February 27 ; E.D.D., December 6. May 29: 12-14 weeks pregnant; B.P., 100/ 64 ; urine, no protein ; weight, 8 st. (50.8 kg.); Hb, $65 \%$. From May 29 to August 17 the B.P. varied between 110/ 66 and $120 / 80$. August 25: admitted with B.P. of $150 / 100$; no proteinuria. B.P. then varied between $140 / 90$ and 156/ 90 ; no symptoms. September 17: sudden appearance of 6 parts of albumin in urine ; oedema ; B.P. rose to $170 / 120$; weight, 8 st. 5 lb. (53 kg.). September 29: spontaneous breech delivery ; S.B. macerated foetus, $2 \mathrm{lb} .6 \mathrm{oz}$. $(1.1 \mathrm{~kg}$.). October 7: B.P., 104/76; trace of albumin in urine. October 9: B.P., $150 / 110$; trace of albumin in urine ; recurrence of symptoms of Raynaud's disease.

Such cases are not common, but they demonstrate that women without detectable stigmata of the cardiovascular-renal system may develop recurrent hypertension, proteinuria, oedema, and other symptoms at about the 30th week of pregnancy in spite of the most careful antenatal care.

*Alb. = proteinuria expressed in parts recorded in Esbach's albuminometer. 
Apart from the preparations women may get from the food office, each who attends the antenatal clinic receives :

Tabellae ferri sulphatis compositae (N.F.), 1 tablet thrice daily. Each tablet contains exsiccated ferrous sulphate, 3 gr. (195 mg.) copper sulphate, $1 / 25 \mathrm{gr}$. (2.4 $\mathrm{mg}$.), and manganese sulphate, $1 / 25$ gr. (2.4 mg.).

Tabellae calcii cum vitamino D (N.F.), 1 tablet thrice daily. Each tablet contains calcium sodium lactate, $7 \frac{1}{2}$ gr. (488 mg.), calcium phosphate $2 \frac{1}{2}$ gr. (163 mg.), and calciferol $1 / 4,800 \mathrm{gr}$ (0.014 mg., which is equivalent to 500 international units of vitamin D).

Those in the antenatal ward are given :

Tabellae ferri sulphatis compositae $(N . F),$.2 t.d.s.

Tabellae calcii cum vitamino $\mathrm{D}(N . F),$.1 t.d.s.

Vitamin $B_{1}, 3 \mathrm{mg}$. t.d.s.

Vitamin C, $25 \mathrm{mg}$. t.d.s.

Capsules containing 4,500 units of vitamin A and 450 units of vitamin D, 1 t.d.s.

Case II was also given stilboestrol, $5 \mathrm{mg}$. t.d.s., working up to $30 \mathrm{mg}$. daily from the time that she booked. She was seen by me almost every week, and put on only $5 \mathrm{lb} .(2.3 \mathrm{~kg}$.) in weight.

A number of gynaecologists have attributed eclampsia and pre-eclampsia to abnormalities in the haemodynamic balance (Beker, 1925, 1948 ; Page, 1939 ; Bouwdijk Bastiaanse and Mastboom, 1950). Bartels (1928) and Wettley (1938) reported that the vascular system was hypoplastic in a high proportion of fatal cases of eclampsia. Kellogg (1945), Newell and Smithwick (1947), and Peet and Isberg (1949) have recorded successful pregnancies following lumbar sympathectomy, but they were dealing with hypertension of the order of $196 / 130$, and were mainly concerned in lowering the systemic blood pressure.

Since 1930 I have maintained that eclampsia is due to faulty nutrition, together with the mechanical disadvantages which are inevitably associated with the pregnant state. It occurred to me that denervation of the internal iliac vessels might in certain cases improve the blood supply to the placenta and prevent the recurrence of toxaemic symptoms in succeeding pregnancies. This procedure, if effective, might operate : (1) by increasing the blood supply to the uterus ; (2) by cutting off afferent and efferent impulses travelling from and to the uterus along sympathetic pathways.

The possible significance of afferent nervous impulses travelling from the uterus is suggested by the following facts. (a) Afferent nervous impulses occasioned by attempts at lumbar puncture in the dog provoked inhibition of water diuresis and proteinuria (Theobald, 1934). (b) The painless introduction of a small dilator through the internal os uteri of a conscious patient and the dilatation of the cervical canal under general anaesthesia may cause the blood pressure to rise by some $10 \mathrm{~mm}$. $\mathrm{Hg}$. Traction on the obstetric forceps during delivery commonly causes a rise in blood pressure which may on occasion exceed $60 \mathrm{~mm}$. Hg. Conversely, cauterization of the uterus by the silver stick may cause a fall of blood pressure from 120/80 to 70/40, a pulse rate of 40 , emesis, and a cold sweat. All these phenomena may occur apart from pain (Theobald, unpublished observations).

Lastly, it may be recalled that Franklin and Sophian (1949) and Franklin (1951) advanced the hypothesis "that toxaemia of pregnancy is, or includes, a progressively increasing tendency for the renal shunt to be brought into operation, and that fatal bilateral cortical necrosis is the maximal, irreversible result of this tendency."

\section{The Operation}

The abdomen is opened by a midline subumbilical incision, the intestines packed off, and the peritoneum divided to expose the bifurcation of the right common iliac artery. This is cleaned with scissors and gauze dissection. Approximately the first $1 \frac{1}{2}$ in. $(3.8 \mathrm{~cm}$.) of the internal iliac artery is stripped and denervated and the corresponding portion of the internal iliac vein is then treated in like manner. After this procedure has been carried out on the left side the abdomen is closed. It must be observed that the proximal portions of the external iliac vessels are inevitably denervated.

The first two operations were performed in January, 1950 . but the original patient has not yet become pregnant. In subsequent operations the stripping of the internal iliac vessels was more extensively carried out so that the obliterated hypogastric arteries were cleaned. Large amounts of nervous and other tissue removed from the blood vessels were fulgurated with the diathermy point. In some cases presacral neurectomy was performed before the abdomen was closed.

The operation is tedious, and the only danger is from haemorrhage, particularly when cleaning the veins deep down in the pelvis. Of the seven patients on whom I have operated only three have become pregnant; their histories are here reported.

\section{Case A}

This patient was aged 33. I have looked after her in all three pregnancies.

First pregnancy, 1947.-L.M.P., October 4, 1946 ; E.D.D., July 11. February 11: booked; 18 weeks; B.P., 140/90. April 24: 28 weeks ; B.P., 200/130 ; alb., 6 parts ; admitted. In addition to the routine dietetic and hygiene treatment, paravertebral blocks on both sides were carried out on several occasions during the first week. April 30:-eyes: right disk, physiological cupping, exudate, haemorrhage; left disk, normal. Headache, vomiting, epigastric pain. Morphine regime. May 16: slight accidental haemorrhage ; B.P., 230/130 ; alb., 4 parts. May 17: intrauterine death of foetus. May 23: B.P., $170 / 110$; alb., 4 parts ; general condition improved. May 24: delivery, following induction of labour, of S.B. male foetus, $2 \mathrm{lb} .8 \mathrm{oz} .(1.1 \mathrm{~kg}$.). It was some weeks before the urine became protein-free. The B.P. subsequently varied for some months between $145 / 85$ and $165 / 120$.

Second pregnancy, 1948.-L.M.P., March 25 ; E.D.D., January 1, 1949. July 6: 12 weeks ; B.P., 130/80-122/94 ; weight, 9 st. $1 \mathrm{lb}$. (57.2 kg.). August 23: B.P., 170/110; alb., 1 part ; weight, 9 st. $6 \mathrm{lb}$. $(57.3 \mathrm{~kg}$.) ; admitted. During the seven weeks in the antenatal ward the blood pressure varied between $140 / 90$ and $170 / 120$. The protein disappeared from the urine, but recurred, although it did not exceed $\frac{1}{2}$ part. The secretion of urine was poor and varied between 20 and $60 \mathrm{oz}$. (570 and $1,700 \mathrm{ml}$.) in 24 hours. October 9: intrauterine death of foetus. October 16: spontaneous delivery of S.B. male macerated foetus, $3 \mathrm{lb} .14$ oz. $(1.8 \mathrm{~kg}$.).

Denervation of the internal iliac vessels, appendicectomy, and partial resection of right ovary were carried out on January 24, 1950. The internal iliac vessels were noticeably small-approximately half the normal size.

Third pregnancy, 1951.-L.M.P., September 5, 1950; E.D.D., June 12, 1951 ; weight, 8 st. 13 lb. (56.7 kg.). The blood pressure varied between $120 / 74$ and $138 / 84$ throughout the antenatal period until the 37th week. No proteinuria was detected. Admitted to ward in 37th week. B.P.. $150 / 90$; weight, 11 st. $1 \mathrm{lb}$. (70.3 kg.). B.P. settled in ward to $130 / 90$. June 11: induction of labour; quinine; 
artificial rupture of membranes (A.R.M.); oxytocin drip. June 13: female infant, $6 \mathrm{lb} .7 \mathrm{oz} .(2.9 \mathrm{~kg}$.). B.P. rose during puerperium to $160 / 105$ and then returned to normal.

\section{Case B}

This patient was 38 years old.

First pregnancy, 1941.-Pregnancy "injected away" at 20 weeks because of "kidney trouble and blood pressure."

Second pregnancy, 1943.- Seventh month; premature S.B. foetus ; "kidney trouble and blood pressure."

Third pregnancy, 1950.-L.M.P., November 12, 1949 ; E.D.D., August 19, 1950. February 2: 12 weeks; B.P., 150/90. March 8: 17 weeks; B.P., 110/70; weight, 9 st. 12 lb. $(57.5 \mathrm{~kg}$.) ; Hb 100\%. From March 8 to June 17 the B.P. varied between $100 / 60$ and 120/80. She then developed hypertension and proteinuria, and was kept in bed at home by her doctor. July 1: admitted to ward; B.P., 168/100. In the ward B.P. varied between 130/84 and $200 / 120$, but during the last two weeks was in the neighbourhood of 160/120. Proteinuria, alb., $2 \frac{1}{2}$ parts. Maximum weight, 11 st. (69.9 kg.). August 1: spontaneous delivery of macerated female child, $4 \mathrm{lb} .10 \mathrm{oz}$. (2.1 kg.). Very small placenta. This patient took cod-liver oil, orange juice, iron, and calcium from the very beginning of pregnancy, and stilboestrol in the antenatal ward. August 26: B.P., $180 / 100$.

Denervation of internal iliac vessels, presacral neurectomy, and partial resection of left ovary were performed on October 24, 1950.

Fourth pregnancy, 1951.-L.M.P., March 24; E.D.D., December 31. June 19: 12-14 weeks pregnant ; B.P., 110/ 70 ; weight 9 st. 2 lb. (58.1 kg.) ; Hb, 75\%. July 27 : went cycling in Scotland. B.P. throughout pregnancy, until 36th week, varied between $110 / 70$ and $120 / 80$. November 30 : 36 weeks ; admitted, as she lives in the country ; B.P., 136/ 90. During second week in hospital B.P. varied between $110 / 70$ and $120 / 80$. Labour induced at 38 weeks, as baby was considered "large enough." December 17: male infant, 7 lb. 8 oz. (3.4 kg.); weight, 11 st. $6 \mathrm{lb}$. (72.6 kg.); $\mathrm{Hb}, 75 \%$.

\section{Case C}

Infertility patient, aged 40, married 14 years.

First pregnancy, 1949.-L.M.P., June 7 ; E.D.D., March 24,1950 . October 4: $12-14$ weeks pregnant ; B.P., 120/ 80 ; weight, 9 st. $10 \mathrm{lb}$. (61.7 kg.). November 30: 22 weeks ; B.P., 170/110 ; alb., + + ; oedema, ++ ; weight, 11 st. 4 lb. (71.7 kg.). Admitted. B.P., 214/120 ; alb., 4 parts ; a few granular and hyaline casts, and red blood cells in urinary deposit ; oedema of face, pitting oedema of knees; short of breath; eyes-striated greyish disks, white streaks along main vessels. "Proctocaine" was injected into broad ligaments, $6 \mathrm{ml}$. on each side. Morphine regime. December 13: blurred, misty vision; everything looked like a shadow ; left eye mainly involved; weight, $10 \mathrm{st}$. $9 \mathrm{lb}$. (67.6 kg.). December 14: some oedema of retinae; tortuous vessels. December 28: intrauterine death of foetus. January 7: macerated male foetus, $3 \mathrm{lb} .8 \mathrm{oz}$. (1.6 kg.).

During her five weeks in hospital the blood pressure at first fell slightly, then rose steeply to $230 / 170$. It then became stabilized at about $190 / 110-220 / 130$, falling in the last week to $160 / 100-180 / 120$. The blood urea reached a maximum of $30 \mathrm{mg}$. per $100 \mathrm{ml}$. Proteinuria varied from 0.5 to 4.5 parts, Esbach. The remarkable feature of this case was the constant excellent output of urine throughout her time in hospital, which reached the level of $205 \mathrm{oz}$. $(5,825 \mathrm{ml}$.) in 24 hours. This in no way suggested the "Oxford shunt." On January $24 \mathrm{Mr}$. Ivor Lloyd reported as follows: "Both eyes show severe hypertensive and albuminuric retinopathy with papilloedema. I fear, however, that the retinal changes indicate severe damage to the vascular system and the kidneys, and the prognosis, as judged from the ophthalmic point of view, is not good. The blood pressure was 160/90." On November 20, 1950, the urea clearance was $142 \%$ of normal. The electrocardiogram showed the usual pronounced left axis deviation of hypertension.

On February 12, 1951, denervation of internal iliac vessels and presacral neurectomy were carried out. Congenital absence of the left kidney was noted.

Second pregnancy.-L.M.P., August 30, 1951 ; E.D.D., June 6, 1952. November 19: B.P., 140/90-occasional beat at 170 ; weight, 9 st. $9 \mathrm{lb}$. (61.2 kg.). February 13: 24 weeks ; B.P., 126/76, this was the only low reading; weight, 9 st. $12 \mathrm{lb}$. (62.6 kg.). The patient was nervous, not very co-operative, and always feared the worst. Her weight remained almost constant at 9 st. $12 \mathrm{lb}$. $(62.6 \mathrm{~kg}$.) for over four months. She did not look well. No proteinuria. April 9 : B.P., 138/96 ; weight, 10 st. 7 lb. (66.7 kg.) ; looked better ; no proteinuria. April 23: B.P., 170/106; weight, 10 st. 12 lb. (68.9 kg.); admitted ; no proteinuria. April 29: B.P. had varied since admission from $150 / 84$ to $160 / 100$; alb., 0.5 part ; foetal heart irregular. In view of the irregular foetal heart caesarean section was performed. Female infant, 5 lb. 2 oz. (2.3 kg.). On May 9 Mr. Ivor Lloyd reported: "Bilateral retinal arteriosclerosis and early retinopathy." After delivery the B.P. varied between $110 / 70$ and $138 / 90$. Apart from the temporary recurrence of an anxiety state the mother did well. The baby flourished.

\section{Denervation of the Aorta, Inferior Vena Cava, and Left Iliac Vessels by Means of $5 \%$ Phenol Solution}

In view of the above results it was decided to determine whether hypertension and proteinuria, once established during pregnancy, could be affected by a comparable procedure.

A primigravida aged 26 was admitted as an emergency case. E.D.D., September 17, 1951 . June 28: B.P., 190/ 100 ; alb., 4 parts ; blood urea, $40-65 \mathrm{mg}$. per $100 \mathrm{ml}$.; maximum concentration of urea, $2 \%$; some oedema; foetal heart very irregular. July 3 : an incision was made through the left loin, the dissection remaining retroperitoneal. The left common iliac artery and vein, the lower part of the abdominal aorta and inferior vena cava (as it was impossible to expose the right common iliac vessels without making another incision), and the left ureter were generously painted with a $5 \%$ solution of phenol: the exposed portion of the left lumbar sympathetic chain was coagulated by diathermy. The patient made an excellent recovery from the operation. From July 4 to August 17 the B.P. varied from $150 / 100$ to $200 / 120$; alb., 2-9 parts. August 18: labour induced at 36th week. August 19: female infant, 2 lb. $14 \mathrm{oz}$. (1.3 kg.); 36 weeks' gestation ; died shortly after delivery. Numerous infarcts in the placenta. May 2, 1952: B.P., 110/76; some protein was still present in the urine.

The abdomen became extremely distended during the last few weeks of pregnancy owing to gaseous distension of the bowel, which took some time to disappear and was still present when she left hospital. It is reasonable to suppose that this distension was due to damage done to the autonomic nervous system by the phenol solution.

\section{Water Diuresis}

A Balloon in Uterus.-A rubber balloon was introduced into the uterus a few days after delivery and distended with water to a pressure of $70 \mathrm{~mm}$. $\mathrm{Hg}$, so that it could be felt as a tensely cystic mass reaching 3 in. $(7.6 \mathrm{~cm}$.) above the symphysis pubis. The distension of the uterus so occasioned did not seem to affect water diuresis, not even when a weight of $1 \frac{1}{2} \mathrm{lb}$. $(0.68 \mathrm{~kg}$.) was attached to the end of the balloon.

Faradic Current to Cervix Uteri.-The cervix uteri was stimulated by a faradic current which was just appreciated but did not cause pain. This procedure was tried on three patients and in no way affected water diuresis. 


\section{Normal Confinements following the Pre-eclamptic Syndrome Occurring in Pregnancy}

During the past five years the few cases in which normal confinements have followed pregnancies in which the preeclamptic symptomatology occurred at or about the 30th week of pregnancy have been collected. They number four in all, with a doubtful fifth case (Case 5).

Case 1.-Patient aged 42, Rh-negative. First pregnancy, 1950: hypertension, $130 / 90$ to $160 / 124$; alb. varied from 0 to 1 part; usual antenatal treatment and stilboestrol ; in antenatal ward five weeks. June 15, 1950: macerated female foetus, $2 \mathrm{lb} .6 \mathrm{oz}$. $(1.1 \mathrm{~kg}$.). The maternal weight increased from $7 \mathrm{st} .11 \mathrm{lb}$. to $8 \mathrm{st}$. $2 \mathrm{lb}$. $(49.4$ to $51.7 \mathrm{~kg}$.). Second pregnancy, January 9, 1951 : spontaneous delivery, female infant, $7 \mathrm{lb} .6 \mathrm{oz}$. $(3.3 \mathrm{~kg}$.). Normal pregnancy.

Case 2.-Patient aged 21. November 6, 1950 : antepartum haemorrhage at home; B.P., 160/110; alb., 22 parts. November 15: severe frontal headache, photophobia. Caesarean section, male infant, $3 \mathrm{lb} .6 \mathrm{oz}$. (1.5 kg.), died two days later. Second pregnancy : slight oedema up to knees and puffiness of face. Neither hypertension nor proteinuria. February 4, 1952: female infant, $5 \mathrm{lb} .6 \mathrm{oz}$. (2.4 kg.), delivered at term.

Case 3.-Patient aged 28. First pregnancy, 1951: normal until 32nd week, then B.P. $160 / 100$; alb., 4-5 parts. Eleven days later : headache; vomiting; B.P., 180/120 ; alb., 24 parts ; male infant, $5 \mathrm{lb} .3 \mathrm{oz} .(2.3 \mathrm{~kg}$.); (36 weeks) did well. When she left hospital the B.P. was still elevated and there was 1 part of albumin in her urine. Second pregnancy normal in every respect, except that her blood pressure was $150 / 90$ when she booked. This was the only abnormal reading. June 18, 1952 : male infant, $7 \mathrm{lb} .12 \mathrm{oz}$. (3.5 kg.).

Case 4.-Patient aged 26. First pregnancy: booked September 12, 1950 ; weight, 8 st. 2 lb. (51.7 kg.) ; B.P., $100 / 60$. December 28: B.P., $180 / 140$; alb., 14 parts; generalized oedema ; admitted. No improvement in antenatal ward. January 1, 1951: 30 weeks pregnant ; induction of labour ; male infant, $3 \mathrm{lb} .9 \mathrm{oz}$. (1.6 kg.) ; died aged 24 hours. Second pregnancy: E.D.D., August 8, 1952. Normal pregnancy; highest B.P., 140/80 ; September 9, 1952: male infant, $9 \mathrm{lb}$. (4.1 kg.).

Case 5.-Patient aged 37. First pregnancy: ? hypertension and proteinuria at 36 weeks; male infant, $4 \mathrm{lb} .8 \mathrm{oz}$. $(2 \mathrm{~kg}$.$) , died. Second pregnancy: twins induced at 26th$ week. S.B., $1 \mathrm{lb} .8 \mathrm{oz}$. and $2 \mathrm{lb} .4 \mathrm{oz}$. (0.68 and $1 \mathrm{~kg}$.). Third pregnancy, 1946, St. Luke's Maternity Hospital: Normal pregnancy. Female infant, $8 \mathrm{lb} .8 \mathrm{oz}$. $(3.9 \mathrm{~kg}$.). Fourth pregnancy, May 5, 1952: Normal pregnancy; female infant, $7 \mathrm{lb} .6 \mathrm{oz}$. $(3.3 \mathrm{~kg}$.).

\section{Living Children, but Not Quite Normal Pregnancies, following Pre-eclamptic Symptomatology}

Case 6.-Patient aged 25. October 5 to November 10 , 1949 : hypertension, $150 / 100$ to $170 / 120$; alb., $2-14$ parts. November 10: female infant, $4 \mathrm{lb} .15 \mathrm{oz} .(2.2 \mathrm{~kg}$.) ; died of bronchopneumonia. Second pregnancy: B.P. varied between $120 / 80$ and $146 / 110$; alb., 1-3 parts. February 5, 1952: male infant, $8 \mathrm{lb} .8 \mathrm{oz}$. (3.9 kg.).

Case 7.-Patient aged 27. First pregnancy, 1947 : abortion at 11 weeks. Second pregnancy, 1950: emergency admission in premature labour with transverse lie; B.P., $140 / 108$ to $160 / 110$; alb., $14-16$ parts ; granular + hyaline casts, many red cells; papilloedema. June 20 : S.B. female foetus, $3 \mathrm{lb}$. 5 oz. (1.5 kg.). September 8, 1951: B.P., 130/ 76 ; urine, no protein. Third pregnancy: hydramnios; B.P., $120 / 76-140 / 94$; alb., 0.5 to 2 parts. March 16: breech, male infant, $7 \mathrm{lb}$., $6 \mathrm{oz}$. $(3.3 \mathrm{~kg}$.).

Case 8.-Patient aged 31. All confinements except the first in this hospital. First pregnancy, 1941 : ? eclamptic fits ; 3 lb. 8 oz. (1.6 kg.) baby ; died same day. Second pregnancy, 1942: hypertension up to $180 / 110$; alb., 15 parts ; S.B. infant. Third pregnancy, 1943 : hypertension up to $150 / 100$; no proteinuria; infant weighed $4 \mathrm{lb}$. (1.8 kg.); died after 36 hours. Fourth pregnancy, 1944 : hypertension up to $150 / 95$; infant, 4 lb. $(1.8 \mathrm{~kg}$.) ; lived a few hours. Fifth pregnancy, 1947: hypertension up to $150 / 85$; infant, 7 lb. 12 oz. $(3.5 \mathrm{~kg}$.); did well. Sixth pregnancy, 1949 : hypertension up to $176 / 100$; no proteinuria ; baby, 7 lb. 4 oz. (3.3 kg.). Seventh pregnancy, 1951 : hypertension; alb., 7 parts; ante-partum haemorrhage ; placenta praevia ; caesarean section; male infant, $5 \mathrm{lb} .3 \mathrm{oz}$ $(2.4 \mathrm{~kg}$.) ; did well ( 37 weeks' gestation). It will be noted that, with the exception of the second pregnancy, all the infants were born alive.

Case 9.-Patient aged 28. First pregnancy: hypertension up to $160 / 118$; no proteinuria ; forceps ; male infant $9 \mathrm{lb} .3 \mathrm{oz}$. (4.2 kg.) ; maternal weight, 13 st. to $13 \mathrm{st} .9 \mathrm{lb}$. $(82.6$ to $86.6 \mathrm{~kg}$.). Second pregnancy : hypertension, $170 /$ 120 ; alb., 12 parts; headache ; dizziness ; poor secretion of urine; caesarean section at 36 weeks; female infant, $6 \mathrm{lb} .14 \mathrm{oz}$. (3.1 kg.). Maternal weight: $14 \mathrm{st} .12 \mathrm{lb}$. $(94.3 \mathrm{~kg}$.) at 17 weeks, $17 \mathrm{st} .2 \mathrm{lb}$. (108.9 kg.) when delivered. Third pregnancy: emergency admission; B.P., 140/100; renal glycosuria; no proteinuria ; caesarean section; male infant, $8 \mathrm{lb} .8 \mathrm{oz}$. (3.9 kg.). Maternal weight: $15 \mathrm{st}$. $11 \mathrm{lb}$. $(100.2 \mathrm{~kg}$.). The weights both of the mother and of the infants were probably significant in this case.

Case 10.-Patient aged 24. First pregnancy: emergency admission on February 4, 1948 ; three weeks in an antenatal ward ; B.P., $220 / 140$; scanty secretion of urine ; alb., 20 parts ; granular and hyaline casts ; blood urea, $60 \mathrm{mg}$ per $100 \mathrm{ml}$; headache ; epigastric pain ; vomiting. Eyes: slight retinal oedema and evidence of hypertension in arteriovenous crossings. February 24: caesarean section ; male infant, $3 \mathrm{lb}$. (1.4 kg.); died on fourth day. Alb., 0.5 part, present in urine when she left hospital. Second. pregnancy: E.D.D., January 14, 1949. Hypertension at 28 weeks; admitted. Maternal weight, 8 st. $2 \mathrm{lb}$. to 9 st. $8 \mathrm{lb}$. $(51.7$ to $60.8 \mathrm{~kg}$.) ; B.P., $140 / 80$ at six weeks ; $140 / 76-155 /$ 95 in ward; no proteinuria. Eyes: fundi satisfactory. January 23: female infant, $5 \mathrm{lb}$. $5 \mathrm{oz}$. $(2.5 \mathrm{~kg}$.) ; did well. - December 21, 1949: B.P., 140/80; neither protein nor abnormal cells discovered in urine.

\section{Discussion of Results}

I recounted the obstetric history of the second " denervation" patient, while she was still pregnant, to a colleague whose opinion is valued very highly throughout the country and asked him what chance he thought she had of a living child. He replied that her only sporting chance was a caesarean section at about the 34th week of pregnancy. She delivered herself of a healthy infant weighing $7 \mathrm{lb} .8 \mathrm{oz}$. $(3.4 \mathrm{~kg}$.), at the $38 \mathrm{th}$ week, after a completely uneventful pregnancy. In my judgment it is most improbable that any of these three patients could have given birth to a living child, and the fact that each of the three has a healthy infant can reasonably be attributed to the operation that was performed.

It is nevertheless necessary to exercise the utmost caution in accepting any such conclusion, and for this reason all the known relevant cases, occurring among some 30,000 deliveries during the past five years in Bradford, have been reviewed. It will be seen that four patients who developed the pre-eclamptic symptomatology at or about the 30th week of their first pregnancies did have normal second confinements. A further five such patients were delivered of healthy children at term, although the pregnancy in each case was complicated by hypertension and in three cases by proteinuria. It must also be recognized that hypertension, proteinuria, oedema, and other symptoms associated with pre-eclampsia do not have the same significance when occurring concomitantly with some forms of antepartum haemorrhage. A patient was recently delivered of a perfectly healthy infant after a normal pregnancy. Her first pregnancy was uneventful, but her second was complicated 
at the 28th week by toxaemic accidental haemorrhage, associated with B.P. $160 / 120 \mathrm{~mm}$. $\mathrm{Hg}$, alb. 14 parts, and epigastric pain. A stillborn foetus, $1 \mathrm{lb} .15 \mathrm{oz} .(0.88 \mathrm{~kg}$.), was delivered by caesarean section because of placenta praevia.

It is therefore my view that this operation, which is not without some risk, should not be performed until after the woman has passed through a second pregnancy during which she has received the most scrupulous care and adequate nutrition. If the pre-eclamptic symptomatology recurs and she again gives birth to a stillborn infant the internal iliac vessels should be denervated. The main disadvantage accruing from this course is that many women, and more husbands (and doctors), feel that after a second such disaster sterilization is indicated. The only exception I would make to this rule is if fulminating symptoms occur before the 26th week of pregnancy, particularly in elderly women. It is because no individual, no matter how great the amount of clinical material he sees, is likely to encounter many patients who would benefit from this operation that I have ventured to publish so small a series of cases. Experience obtained in other centres may not only lead to happiness in barren homes but may shed further light on the aetiology of eclampsia.

A few clinical points may be mentioned. All the women were reasonably healthy in the non-pregnant state, except for some slight degree of hypertension, and such tests as were carried out revealed no abnormality of renal function. Recurrent pre-eclampsia occurring at or about the 30th week of pregnancy cannot reasonably be attributed to abnormal afferent impulses arising in an overdistended uterus, particularly as the foetus is usually unduly small. A study of the cases reported does not reveal that any sudden or great increase in weight characterized more than two of the pregnancies. Case $A$, the first of the denervation cases, put on only $5 \mathrm{lb}$. $(2.3 \mathrm{~kg}$.) in the seven weeks of her second pregnancy, during which the pre-eclamptic syndrome developed. She put on over 2 st. (12.7 kg.) in her successful third pregnancy. Case $C$ did increase her weight by $22 \mathrm{lb}$. (10 kg.) between the 14 th and the $22 \mathrm{nd}$ week of her first pregnancy, but she lost $9 \mathrm{lb}$. $(4 \mathrm{~kg}$.) during the next fortnight.

It is generally agreed that the above symptomatology is often associated with a scanty secretion of urine, but this is not always the case. Case $\mathrm{C}$, who possessed only one kidney, passed urine very freely throughout her stay in the antenatal ward, and actually passed $205 \mathrm{oz}$. $(5,825 \mathrm{ml}$.) in a 24-hour period. At that time the changes in her retinae were marked.

\section{Nutrition of the Placenta}

It might be conjectured that imperfect nutrition of the placenta, particularly in those critical weeks while it is being formed, might result in: (a) premature birth of the foetus ; $(b)$ certain foetal malformations; $(c)$ death of the foetus, without any maternal toxaemic symptoms ; $(d)$ death of the foetus associated with ante-partum haemorrhage and certain types of accidental haemorrhage; and (e) preeclampsia and eclampsia, with or without death of the foetus.

The imperfect nutrition of the placenta might be either qualitative or quantitative, the former defect being due to imperfect nutrition of the mother and the latter to the deficient volume of blood which reaches the placenta. This volume is determined by the actual cross-sections of the arteries concerned, which could theoretically be reduced by spasm. The internal iliac arteries were very noticeably reduced in size in two of the patients operated on, and in one were not much larger in diameter than the radial artery. It has already been mentioned that Bartels (1928) and Wettley (1938) reported that a hypoplastic vascular system was often associated with eclampsia.

Such speculation is attractive and would not appear to be contradicted by known facts. It must, however, be borne in mind that the number of pregnancies which cannot be brought to a successful conclusion by thorough antenatal care is extremely small. Further, even if it be assumed that occasional cases are encountered in which the blood supply to the placenta is so limited by the actual size of the arteries directly or indirectly supplying the uterus that the pre-eclamptic syndrome invariably supervenes, it by no means follows that pre-eclampsia and eclampsia can invariably be attributed, either in part or in whole, to imperfect nutrition of the placenta. As well might it be argued that blindness is invariably due to opacities in the cornea.

\section{Significance of Afferent Nervous Impulses Arising in the Uterus}

It may be assumed that any increased blood supply afforded to the placenta was effected through the division of efferent nerves which constricted the internal iliac arteries. No evidence was obtained to show that afferent fibres arising in the uterus play any part in the preeclamptic symptomatology. Considerable distension of the post-partum uterus with a rubber balloon filled with water exerted no effect either on the blood pressure or on water diuresis ; neither did a faradic current delivered to the cervix by means of a twin electrode. These experiments were, however, of short duration, and the possibility that prolonged stimulation of these nerves might interfere with the secretion of urine cannot be excluded.

Painting the lower portions of the abdominal aorta and inferior vena cava, the internal iliac vessels, and the ureter on the left side with a $5 \%$ solution of phenol, together with the destruction of the lower part of the lumbar sympathetic chain, caused no measurable alleviation of symptoms in a pre-eclamptic patient, although the pregnancy was allowed to continue for six weeks after the operation. The foetus did survive, although it did not increase much in size. Bayliss and other physiologists have used this strength of phenol solution for the destruction of sympathetic nerve fibres, and Doppler (1925) introduced the method into surgery. It may be supposed that many nerve fibres were destroyed, but neither the increase of blood supply afforded to the placenta at this stage nor the cutting off of afferent impulses served to ameliorate the preeclamptic symptomatology. It is of interest to note that the wide destruction of pelvic sympathetic nerves, combined with presacral neurectomy, caused no obvious diminution of the pains of labour.

\section{Conclusion}

It is suggested that denervation of the internal iliac vessels is a justifiable and worth-while procedure in women who have twice suffered from pre-eclampsia, associated with death of the foetus, at or about the 30th week of pregnancy. It is possible that denervation of the internal iliac artery on either side will suffice, without stripping the veins, and if this be the case the operation will be shorn of its main danger and could be advocated more freely. Presacral neurectomy was not performed in the first successful case and is most likely unnecessary. These and other cases provide no justification for the assumption that prolonged hypertension and proteinuria occurring during pregnancy cause either chronic nephritis or hypertension.

\section{Summary}

A woman in whom the eclamptic syndrome does not manifest itself before the 38th week of her first pregnancy almost invariably has subsequent nørmal pregnancies.

If, however, the pre-eclamptic syndrome occurs at or about the 30th week of pregnancy, notwithstanding adequate antenatal care, the same symptomatology is likely to recur in subsequent pregnancies and to manifest itself at about the same period of gestation. The foetus, moreover, is likely to be very small. 
Three successful pregnancies subsequent to denervation of the internal iliac vessels are reported. The first patient had had two stillbirths and the second three stillbirths. The third patient had had a fulminating attack of pre-eclampsia at the $22 \mathrm{nd}$ week of her first pregnancy and possessed but one kidney.

It is suggested that adequate nutrition of the placenta, particularly when it is being formed, is essential to a normal pregnancy, and that in a very few cases the actual size of the internal iliac arteries makes this impossible in the presence of normal arterial tone.

The fact that adequate nutrition of the placenta is essential to a normal pregnancy by no means excludes the necessity for the proper nourishment of the maternal organs, and in the vast majority of cases the one requisite is impossible apart from the other.

No evidence was obtained to suggest that the preeclamptic syndrome can be attributed to afferent nerve impulses arising in the uterus.

The cases studied provide no support for the view that long-sustained hypertension and proteinuria during pregnancy cause either chronic nephritis or hypertension, or can be attributed to a " renal shunt."

\section{REFERENCES}

Bartels (1928). Quoted by Bouwdijk Bastiaanse and Mastboom (1950). Bartels (1928), Quoted by Bouwdijk Bastiaanse

Beker, J. C. (1925). Ned. T. Geneesk., 69, 2009. 756

Bouwdijk Bastiaanse, M. A. van, and Mastboom, J. L. (1950). Toxaemias of Pregnancy, p. 182 Ciba Foundation Symposium, London.

of Pregnancy, p. 182 . Ciba Foundation
. Klin., 21, 547.

Doppler, K. (1925). Med. Klin., 21, 547.

Franklin, K. J. (1951). Proc. roy. Soc. Med., 44,

Kellogg, F. S. (1945). Clinics, 4, 585.

and Smithwick, R. H. (1947), New, Engl, J Med, 236, 851

Page, E. W. (1939). Amer. J. Obstet. Gynec., 37, 291

Peet, M. M., and Isberg, E. M. (1949). Amer. J. med. Sci., 217, 530.

Theobald, G. W. (1934). J. Physiol., 81, 243.

Wettley (1938). Quoted by W. Haupt, Arch. Gynäk., 166, 71

\section{THE PSYCHIATRIST AND COMPENSATION NEUROSES*}

\author{
BY \\ JOHN DUNNE, M.B., D.P.H. \\ Professor of Psychiatry, University College, Dublin
}

The term "neurosis" ras used in litigation is notorious for the looseness of its application. It is in fact a term which is applied generally to describe any mental disorder, short of an obvious psychosis, following an injury.

As a preliminary, therefore, to any discussion on the question of compensation neuroses, I think it advisable to refer to the various types of mental disorder which are associated with trauma. The obvious psychotic results of brain-tissue damage from direct injury vary from the acute traumatic deliria to mental defect. The post-traumatic constitution of Adolf Meyer and the post-concussional or contusional states of Henderson may appear obscure to the general practitioner or to the lawyer but are none the less definite morbid conditions of grave significance, undoubtedly brought about by tissue damage. They have a reasonably objective symptomatology, and in many cases have a positive electroencephalographic reading. The psychoses, which are less obviously associated with direct brain injury, include the various well-recognized constitutional syn-

*Read in opening a discussion in the Section of Psychiatry at the Annual Meeting of the British Medical Association, Dublin, 1952 . dromes of schizophrenia, manic or depressive states, and paranoia. The attributability of these constitutional syndromes to injury, either with or without head injury, depends very largely on the factor of coincidencenamely, the development of the psychosis in a previously normal person within a reasonable time after the injury. The fact that there may have been evidence of cerebral damage, such as amnesia or other confusional signs, is not in itself complete assurance that the injury was responsible for the development of the psychotic state. It is merely corroborative of the supposition based on the chronology of evidence that the psychosis was precipitated by the injury.

To come to the question of so-called compensation neuroses, it is a first essential to define as accurately as possible the meaning of neurosis. It may be said at once that, except in so far as neuroses associated with injury involve the question of compensation, there is no such entity as a compensation neurosis. Such an appellation might be applied with equal justification to more obvious results of injury-for example, compensation fracture, dislocations, etc.

The neuroses which follow an injury do not in any way differ symptomatologically or otherwise from the neuroses met with daily in psychiatric clinics, where no question of compensation arises, but merely the question of treatment. They are well-defined syndromes of varying degrees of severity, and, while there may be overlapping of symptoms complicating the diagnosis, they have been classified under well-recognized headings of neurasthenia, anxiety states, obsessional states, and hysteria.

Henderson, in his textbook of psychiatry, makes a distinction between traumatic neuroses and traumatic psychoneuroses, attributing the former to physical damage and the latter to the psychological effect on the personality. Most authors agree that the extent or site of the injury has no specific bearing on the nature or type of the neurosis. This has been conclusively shown in the studies of the neuroses occurring in large groups during the war.

The 'work of Parfitt on neuroses in the R.A.F., of Guttman and Baker on neuroses in firemen during the war, and of Linford Rees on neuroses in women in auxiliary services all point to the same conclusion, that the primary aetiological factor in all cases of neurosis is a psychological predisposition, which may become manifest only when exposed to certain forms of stress. The term "neurosis of psychoneurosis" must therefore be taken as one and the same thing, with the same aetiological mechanism.

\section{Malingering}

In the approach to a case of alleged neurosis in which compensation is involved, the first essential is to make a reasonably accurate diagnosis of the nature of the neurosis, and the examining physician should endeavour to satisfy himself whether he is dealing with one of the accepted well-recognized and well-defined forms. When he has concluded his investigations he should be able to state whether the case comes under the heading of a neurasthenia, an anxiety state, an anxiety hysteria, a hysteria, or an obsessional neurosis. If he has succeeded in making a diagnosis under any of these categories he must then satisfy himself that the signs and symptoms on which he has based his opinion are not simulated. To rule out simulation is not always an easy task. The malingerer can be very cunning, as the prize is great. Malingering can be ruled out only by the careful correlation of signs and symptoms by a 